\title{
Effects of wintering waterfowl's feces on nutrient dynamics of paddy fields and rice growth
}

\author{
Gwang Moon Lee, Heung-Tae Kim and Jae Geun Kim* \\ Department of Biology Education, Seoul National University, Seoul 151-748, Korea
}

\begin{abstract}
This experiment was conducted to investigate the effects of the addition of wintering waterfowl's feces prior to planting rice on nutrient dynamics, rice growth, and decomposition of rice straws in a controlled mesocosm. Waterfowl's feces and rice straws were placed on paddy soils in a mesocosm and the water level maintained at $5 \mathrm{~cm}$. The amounts of supplied feces were 0 (control), 222, and $444 \mathrm{~g} / \mathrm{m}^{2}$. While the addition of feces showed no immediate effects, nutrients in the surface water increased in the month following treatment. Nutrients increased to a greater degree in the treatments with more feces added. Simultaneously, the decomposition of rice straws was promoted, indicating that more nutrients would be made available over time. The rice showed high productivity in the period during which nutrient level was increased, when rice needs more nutrients for the tillering stage. Therefore, the wintering waterfowl's feces could be associated with increased productivity during the growing season of rice through promoting nutrient supply and rapid decomposition of rice residue.
\end{abstract}

Key words: decomposition, fecal addition, nutrient, productivity, wintering waterfowl

\section{INTRODUCTION}

A large colony of birds can have a profound effect on the environment, and a large-scale bird migration has significance in nutrient cycling. In particular, bird feces provide an outside nutrient source to environments in which they dwell (Manny et al. 1994, Tomassen et al. 2005, Chaichana et al. 2010). Subsequently, continuous inhabitation of birds can have an important impact on the plant community in their habitats (Ishida 1997, Nam et al. 2008).

Many migratory waterfowl inhabit wetland areas and form large flocks. The environment and plants around the wetlands they inhabit can be influenced by their excretion (Manny et al. 1994). South Korea is home to many wintering habitats of migratory waterfowl (Lee et al. 2000, 2001). In particular, the Han River estuary in winter 2008 recorded about 100,000 birds of 53 different species, which were dominated by waterfowl such as the white-fronted goose and bean goose (Kang et al. 2008). Many species of wintering bird are observed in rice paddy fields near the estuary. The paddy fields in winter supply wintering waterfowl with a foraging and resting place. They stay form around October to March. As large flocks of waterfowl stay in the paddy fields in winter, the addition of their feces can be influential on the nutrient status for the growth of rice in the following spring.

However, there is a paucity of studies analyzing the impacts that the feces of wintering waterfowl have on rice growth in the locations where they forage and live during the winter months. Although there are studies on waterfowl's feces, the research has been conducted in lakes and ponds of deep water (Unckless and Makarewicz 2007, Na-

\section{Open Access http://dx.doi.org/10.5141/JEFB.2012.034}

This is an Open Access article distributed under the terms of the Creative Commons Attribution Non-Commercial License (http://creativecommons org/licenses/by-nc/3.0/) which permits unrestricted non-commercial use distribution, and reproduction in any medium, provided the original work is properly cited.
Received 10 September 2012, Accepted 25 September 2012

*Corresponding Author

E-mail: jaegkim@snu.ac.kr

Tel: +82-2-880-7896 
kamura et al. 2010), which is a very different environment from paddy fields, wetlands composed of shallow water. Other studies on paddy fields looked at the effect of added feces during the growth period (Isobe et al. 2005, Chengfang et al. 2008). However, the wintering waterfowl's feces are added to the paddy fields in the Han River estuary only during the early season before rice growth. Thus, we have on information about the effect of feces supplied by wintering waterfowl on the environment of paddy fields and on rice growth during the growing season.

The addition of fecal matter can cause a change in the decomposition rate of the previous season's plant matter, thereby increasing the amount of available nutrients to new plants over time (Kelly and Henderson 1978, Elwood et al. 1981). Plant residues are an important source of nutrients in the soil, indicating that decomposition of rice straws could be an influential factor to nutrient cycling in paddy fields. In particular, the synchronization of nutrient release from plant residues and uptake by plants is an important matter affecting the growth of rice plants (Villegas-Pangga et al. 2000, Rejmánková 2011).

The purpose of this study was to investigate the effects of waterfowl's feces, added to paddy fields before rice growth, on the nutrient status of the paddy field, rice growth, and the decomposition of rice straws during the period of rice plant growth. A greenhouse experiment was designed to simulate the fecal additions by waterfowl before rice growth in a variable-controlled environment.

Table 1. Analysis of paddy soil, feces and straw used in the experiment

\begin{tabular}{lccccc}
\hline & $\begin{array}{c}\mathrm{TN} \\
(\mathbf{m g} / \mathbf{k g})\end{array}$ & $\begin{array}{c}\mathrm{NO}_{3}{ }^{-} \\
(\mathbf{m g} / \mathbf{k g})\end{array}$ & $\begin{array}{c}\mathrm{NH}_{4}{ }^{+} \\
(\mathbf{m g} / \mathbf{k g})\end{array}$ & $\begin{array}{c}\mathrm{TP} \\
(\mathbf{m g} / \mathbf{k g})\end{array}$ & $\begin{array}{c}\mathrm{PO}_{4}{ }^{3-} \\
(\mathbf{m g} / \mathbf{k g})\end{array}$ \\
\hline Paddy soil & 2,128 & 109 & 473 & 544 & 190 \\
Feces & 6,939 & & & 991 & \\
Straw & 4,567 & & & 605 & \\
\hline
\end{tabular}

$\mathrm{TN}$, total nitrogen; TP, total phosphorus.

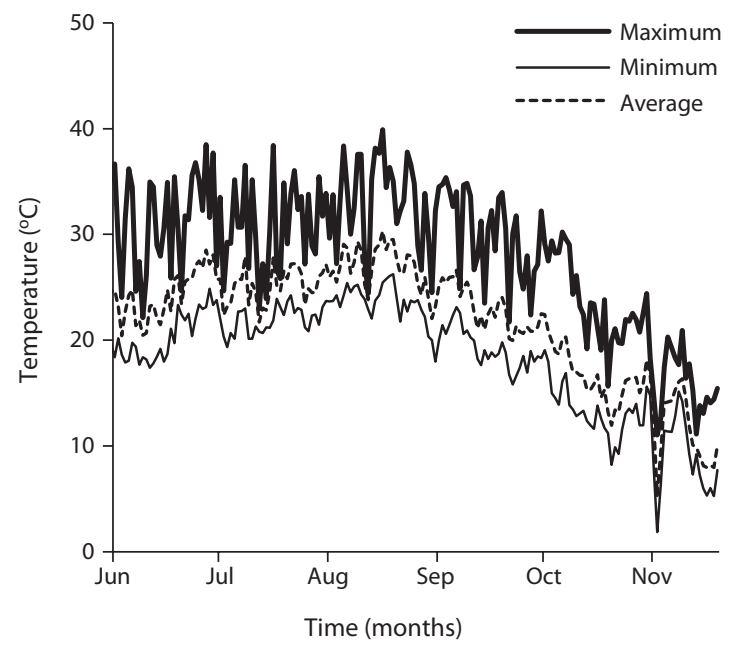

Fig. 1. Temperature variation at study site in 2009.

\section{MATERIALS AND METHODS}

The experiment was conducted in a greenhouse at Seoul National University from 27 May 2009 to 13 October 2009. Maximum and minimum temperatures fluctuated between $38^{\circ} \mathrm{C}$ and $15^{\circ} \mathrm{C}$ and between $21^{\circ} \mathrm{C}$ and $8^{\circ} \mathrm{C}$, respectively (Fig. 1). Plastic pots $(50 \times 36 \times 30 \mathrm{~cm})$ were used for growing rice and filled with $25.41 \mathrm{~kg}$ of soil, collected from harvested paddy fields and sieved with $2 \mathrm{~mm}$ mesh, to a depth of $10 \mathrm{~cm}$ (Table 1). The water level was maintained with tap water at $5 \mathrm{~cm}$ above the soil surface.

Three treatments were studied: fecal additions of 0,40 , and $80 \mathrm{~g}$ per pot (Table 2). The addition of 40 and $80 \mathrm{~g}$ of fecal matter was calculated to result in a distribution of 222 and $444 \mathrm{~g} / \mathrm{m}^{2}$, respectively. We used this amount based on the following data. Daily feces amounts of goose and duck are $32.76 \mathrm{~g}$ and $15.07 \mathrm{~g}$, respectively (Manny et al. 1994) and they stay in paddy field for $7.9 \%$ and $6.7 \%$ of a day, respectively (Pae et al. 1995) from mid-August

Table 2. Input amount of waterfowl feces

\begin{tabular}{|c|c|c|c|c|c|c|}
\hline Study & Wetland type & Input regime & Period & Total input $\left(\mathrm{g} / \mathrm{m}^{2}\right)$ & $\mathrm{N}\left(\mathrm{g} / \mathrm{m}^{2}\right)$ & $P\left(g / m^{2}\right)$ \\
\hline Purcell and Goldsborough (1996) & Marsh & Every week & 5 July-23 August & 488 & 6.18 & 1.98 \\
\hline \multirow[t]{2}{*}{ Pettigrew et al. (1998) } & Marsh & Twice & 28 June, 21 July & 230 & 66.76 & 36.14 \\
\hline & & & & 23 & 6.67 & 3.61 \\
\hline \multirow[t]{2}{*}{ Isobe et al. (2005) } & Paddy & Every week & 11 July- 6 August & 15.72 & 0.42 & - \\
\hline & & & & 18.52 & 0.49 & - \\
\hline \multirow[t]{2}{*}{ Unckless and Makarewicz (2007) } & Pond & Every 3 day & 28 June-12 August & 26.61 & 0.06 & 0.01 \\
\hline & & & & 67.7 & 0.14 & 0.02 \\
\hline \multirow[t]{2}{*}{ In this study } & Paddy (mesocosms) & Once & 25 June & 444 & 3.08 & 0.44 \\
\hline & & & & 222 & 1.54 & 0.22 \\
\hline
\end{tabular}


to mid-March (about 150 days). This makes $151 \mathrm{~g}$ to 388 $\mathrm{g}$ feces $\mathrm{m}^{-2} \mathrm{y}^{-1}$. Unlike other studies in which experimental protocol included the continuous addition of feces throughout the growth period, we added the experimental amount of feces to the pots only at the beginning of the experiment. The feces for the experiment were collected from the paddy fields around the Han River in February, and total nitrogen (TN) and total phosphorus (TP) were analyzed immediately (Table 1). The feces were stored in a refrigerator at $4{ }^{\circ} \mathrm{C}$ and pulverized after air-drying. Each treatment had four replicates, and a total of twelve pots are arranged so that pots receiving the same treatment were not adjacent to one another.

Rice straws were air-dried at room temperature and the rice straws to be used in litter bags were dried at $60^{\circ} \mathrm{C}$ for $48 \mathrm{~h}$. The rice straws were then cut to a length of $5 \mathrm{~cm}$ and $5 \mathrm{~g}$ were placed into each nylon litter bag $(5 \mathrm{~cm} \times 5 \mathrm{~cm})$ with $1 \mathrm{~mm}$ mesh. Eight litter bags were put into each pot, to which rice seedlings at the two-leaf stage were transplanted. After the harvest, the litter bags were collected and TN and TP were analyzed.

A sample of $100 \mathrm{~mL}$ of water was gathered from each pot every two weeks for the first month, then once a month for the duration of the study. The sampled water was filtered and stored at $-20^{\circ} \mathrm{C}$ until analysis of available nitrogen and phosphorus was performed. Nitrate $\left(\mathrm{NO}_{3}{ }^{-}\right)$, ammonium $\left(\mathrm{NH}_{4}{ }^{+}\right)$, and phosphate $\left(\mathrm{PO}_{4}^{3-}\right)$ were analyzed by the hydrazine method (Kamphake et al. 1967), indophenol method (Liddicoat et al. 1975) and ascorbic acid reduction method (Solorzano 1969), respectively.

Soil samples were taken at the beginning and end of the experiment. TN and TP in the soil samples were analyzed at the National Instrumentation Center for Environmental Management at Seoul National University. Available nitrogen and phosphorus were extracted using $\mathrm{KCl}$ extraction and Truog's method, respectively (Kim et al. 2004). Nitrate, ammonium and phosphate in the extracted solutions were analyzed using the same methods used for water sample analysis. To investigate whether a change in rice growth occurred, the number and height of shoots in each pot were measured and the average and total sum of shoot length calculated. After conducting the first measurement at the end of the first week, measurements were conducted every two weeks. At the end of the experiment, the rice was collected from each pot for measurement of total biomass. Shoots and roots were collected at the same time. Collected roots were washed with tap water and dried at $60^{\circ} \mathrm{C}$ for $48 \mathrm{~h}$, then weighed.

The litter bags, used to measure the decomposition rate of the rice straws, were collected at $0,1,3,6,10,13,17$, and 21 weeks. Collected litter bags were carefully washed and dried at $60^{\circ} \mathrm{C}$ for $48 \mathrm{~h}$, weighed, and the weight loss ratio calculated.

A one-way ANOVA $(P<0.05)$ and Tukey's post hoc test were used to statistically examine the results at each sampling time.

\section{RESULTS}

\section{Available nutrients in the surface water}

Nutrients in the surface water initially increased at a high rate, then appeared at decreasing rate over time with only a small quantity left at the completion of the study (Fig. 2). The plots containing $80 \mathrm{~g}$ of feces were found to contain a higher nutrient content compared with other plots during the period of nutrient increase. Nitrate increased rapidly at the fourth week and then largely decreased at the eighth week (Fig. 2a). Nitrate content in the plots containing $80 \mathrm{~g}$ of feces was significantly different from other plots. Ammonium content was highest in the second week under all experimental conditions without a significant difference among the different plots. Ammonium content in the plots containing $80 \mathrm{~g}$ of feces was significantly different from control at the fourth week, and ammonium content in the plots containing $40 \mathrm{~g}$ of feces was significantly different from that found in the control at the eighth week (Fig. 2b). Phosphate increased at the fourth week and immediately decreased, being significantly different in the plots containing $80 \mathrm{~g}$ of feces from all other plots in the study (Fig. 2c).

\section{Available nutrients in the soil}

Each nutrient in the soil decreased differentially by the end of the study (Fig. 3). The content of TN was $2,128 \mathrm{mg} /$ $\mathrm{kg}$ at week 0 . After harvest, the control plots, plots containing $40 \mathrm{~g}$ of feces, and plots containing $80 \mathrm{~g}$ of feces had $1,821 \pm 32 \mathrm{mg} / \mathrm{kg}, 1,930 \pm 83 \mathrm{mg} / \mathrm{kg}$, and 1,904 $\pm 46 \mathrm{mg} /$ $\mathrm{kg}$, respectively (Fig. 3a). The initial nitrate content in all plots was $109 \mathrm{mg} / \mathrm{kg}$. After the harvest, nitrate content in the control plots, plots containing $40 \mathrm{~g}$ of feces, and plots containing $80 \mathrm{~g}$ of feces was $3.3 \pm 0.4 \mathrm{mg} / \mathrm{kg}, 4.1 \pm 0.7 \mathrm{mg} /$ $\mathrm{kg}$, and $3.3 \pm 0.4 \mathrm{mg} / \mathrm{kg}$, respectively, indicating that the available nitrate was almost entirely exhausted (Fig. 3b). The initial content of ammonium in all plots was $473 \mathrm{mg} /$ $\mathrm{kg}$ and decreased to $276 \pm 27 \mathrm{mg} / \mathrm{kg}$ in the control, 285 $\pm 25 \mathrm{mg} / \mathrm{kg}$ in plots containing $40 \mathrm{~g}$ of feces, and $302 \pm$ $43 \mathrm{mg} / \mathrm{kg}$ in the plots containing $80 \mathrm{~g}$ of feces, without a 

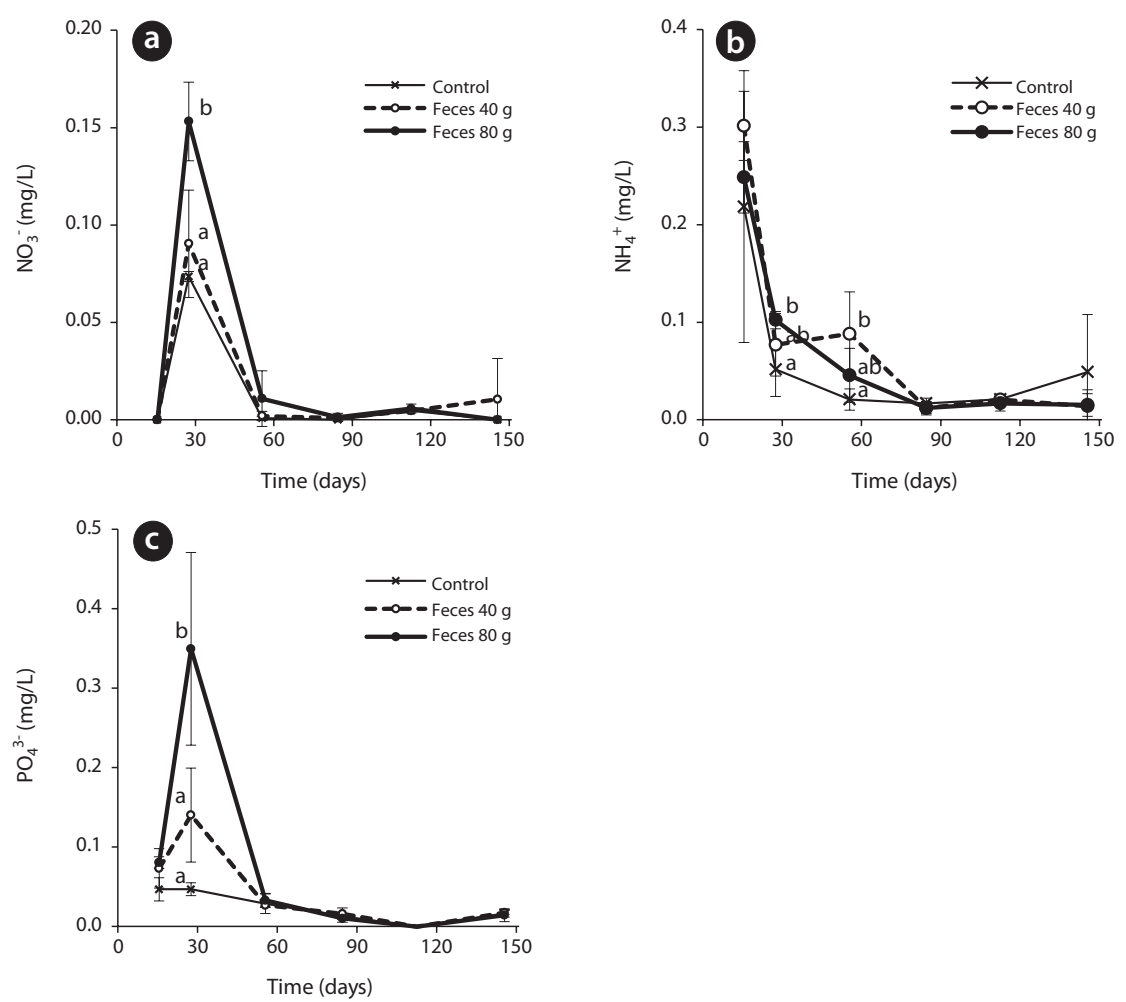

Fig. 2. Change of nitrate $\left(\mathrm{NO}_{3}{ }^{-}\right)(\mathrm{a})$, ammonium $\left(\mathrm{NH}_{4}^{+}\right)(\mathrm{b})$, and phosphate $\left(\mathrm{PO}_{4}{ }^{3-}\right)(\mathrm{c})$ in the surface water of the plots during the experiment. Error bars indicate 1 standard error. Alphabets indicate the result of Tukey's post hoc test.
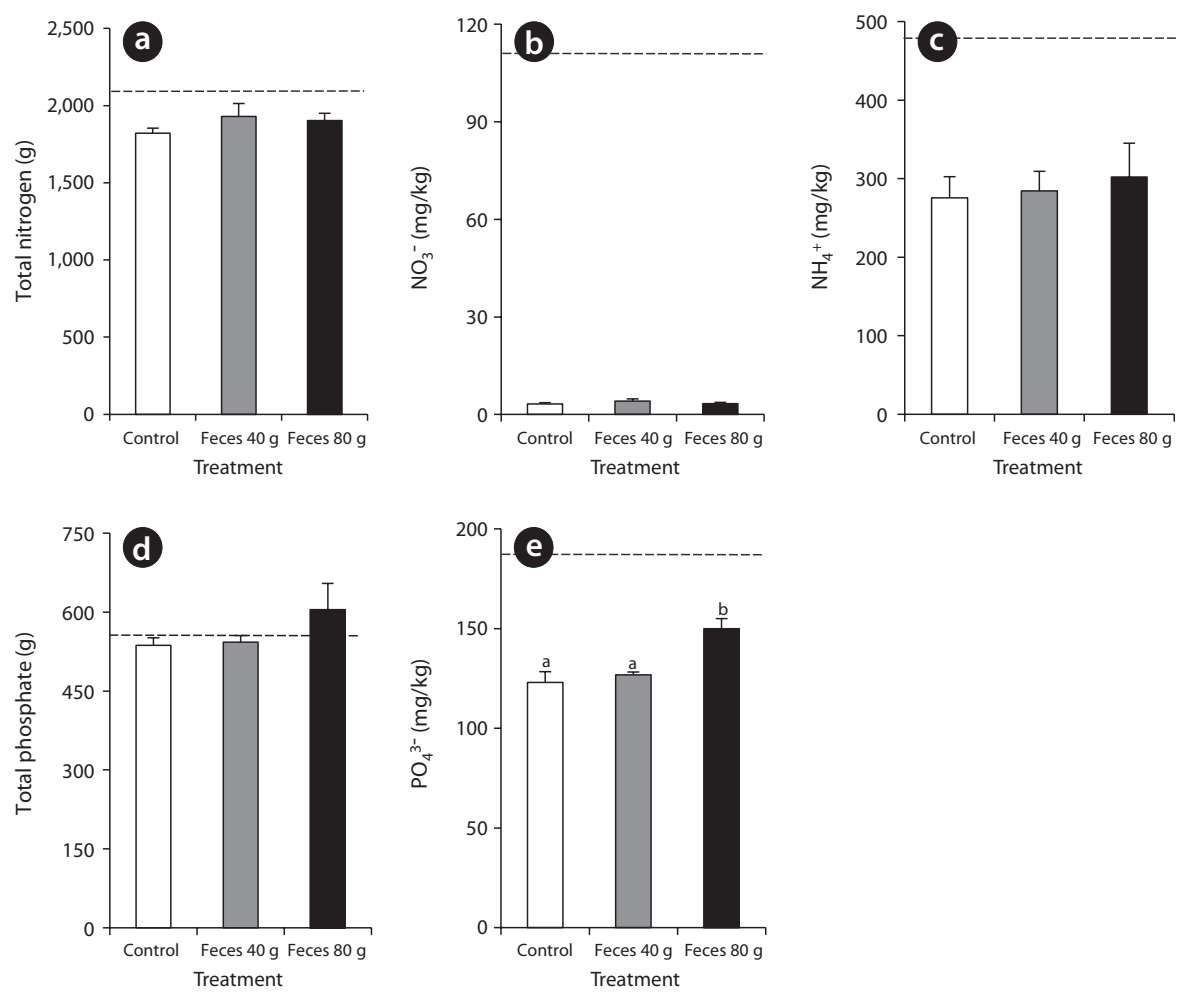

Fig. 3. Analysis of soil after harvest for each experimental condition. Error bars indicate 1 standard error. Alphabets indicate the result of Tukey's post hoc test. Spotted lines indicate initial state of soil. 

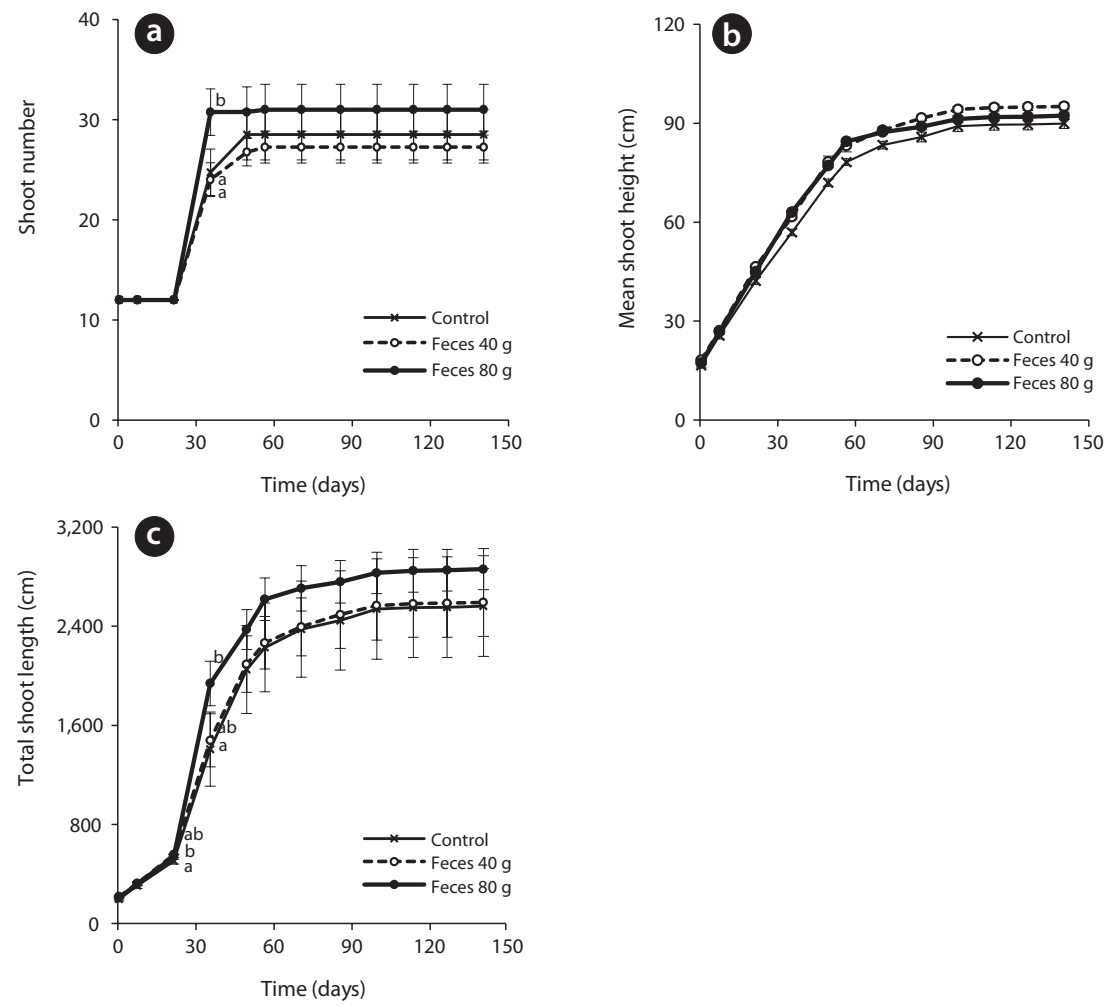

Fig. 4. Change of shoot number (a), mean shoot height (b), and total sum of shoots' height (c) in growth period. Error bars indicate 1 standard error. Alphabets indicate the result of Tukey's post hoc test.

significant difference in the amount of ammonium consumed among the plots (Fig. 3c). TP and phosphates in the soil showed a slight decrease over the period of the experiment. TP was $544 \mathrm{mg} / \mathrm{kg}$ at the beginning of the experiment. After the harvest, TP in the control plots and the plots containing $40 \mathrm{~g}$ of feces was $537 \pm 14 \mathrm{mg} /$ $\mathrm{kg}$ and $543 \pm 12 \mathrm{mg} / \mathrm{kg}$, respectively. In contrast, the TP content in the plots containing $80 \mathrm{~g}$ of feces increased to $605 \pm 49 \mathrm{mg} / \mathrm{kg}$ (Fig. 3d). The initial content of phosphates was $190 \mathrm{mg} / \mathrm{kg}$ at the beginning of the experiment. After the harvest, phosphate content in the control plots, plots containing $40 \mathrm{~g}$ of feces, and the plots containing $80 \mathrm{~g}$ of feces was $123 \pm 6 \mathrm{mg} / \mathrm{kg}, 127 \pm 2 \mathrm{mg} / \mathrm{kg}$, and $150 \pm 5 \mathrm{mg} /$ kg, respectively (Fig. 3e).

\section{Effect of different amount of feces on height and biomass of rice}

The rice showed a sharp increase in growth at the beginning of the tillering period at the fifth week of the experiment, and the total of the shoot height increased in the presence of added feces (Fig. 4). The shoot number began to differ among the experimental conditions at the tillering period. The plots containing $80 \mathrm{~g}$ of feces had the largest number of shoots, $31 \pm 1$ shoots. There was no significant difference between the control, $28 \pm 3$ shoots, and the plots containing $40 \mathrm{~g}$ of feces, $27 \pm 2$ shoots. The plots containing $40 \mathrm{~g}$ of feces had the highest average of shoot height, $95 \pm 1 \mathrm{~cm}$, followed by the shoot height in the plots containing $80 \mathrm{~g}$ of feces, $92 \pm 1 \mathrm{~cm}$, and the control, $90 \pm 1 \mathrm{~cm}$. The total of shoot height showed a significant difference between the plots with feces and without feces at the third week, and between the control and the plots containing $80 \mathrm{~g}$ of feces at the sixth week. Following the sixth week, although shoot height among the different plots were not statistically different, the average value showed an increasing trend in the presence of feces. At the experiment's end, the average value of shoot height in the control plots, plots containing $40 \mathrm{~g}$ of feces, and plots containing $80 \mathrm{~g}$ of feces were 2,563 $\pm 203 \mathrm{~cm}$, $2,671 \pm 137 \mathrm{~cm}, 2,861 \pm 83 \mathrm{~cm}$, respectively. The biomass of rice showed an increasing trend in the presence of feces. The dried biomasses collected from the control plots and plots containing $40 \mathrm{~g}$ of feces were $159 \pm 4.7 \mathrm{~g}$ and 162 $\pm 6.5 \mathrm{~g}$, respectively. The plots containing $80 \mathrm{~g}$ of feces had a significantly different biomass, $177 \pm 1.4 \mathrm{~g}$, compared to both the control and plots containing $40 \mathrm{~g}$ of feces. 


\section{Decomposition rate of straw with different amount of feces}

Although the decomposition of the rice straw showed a significant difference among the plots during the period from the first week to the sixth week, there was no significant difference in the final analysis. The decomposition rate in the plots containing $80 \mathrm{~g}$ of feces was significantly higher compared to the control and plots containing $40 \mathrm{~g}$ of feces at the third week. After the third week, the decomposition rates in the control and the plots containing $40 \mathrm{~g}$ of feces changed in a similar trend, and the plots containing $80 \mathrm{~g}$ of feces had a relatively higher rate of decomposition but without statistical significance.

\section{DISCUSSION}

We found that addition of waterfowl's fecal matter had an effect on the water and soil chemistry, the decomposition rate of rice straws, and influenced plant growth. In particular, the effect was most distinct in the plots containing $80 \mathrm{~g}$ of feces. The content of nitrate and phosphate in the surface water increased rapidly at the fourth week in all treatments. During this time, the nutrient content in the surface water was different among the treatments, as well as, the decomposition rate of rice straws and the total sum of shoot height. However, from then on, as the contents of nitrate and phosphate decreased with rice growth, the difference among the treatments ceased to exist. However, the final biomass measurement from the plots containing $80 \mathrm{~g}$ of feces was significantly greater when compared with other treatments.

The fecal impacts appeared at about one month from addition in the present study (Fig. 2). The time over which nutrient content was increased in the surface water did not depend on the amount of feces in each treatment, but the quantities of nutrients present did. Natural environments influence the time during which feces begin to have an effect on nutrient content in bodies of water. Ganning and Wulff (1969) and Pettigrew et al. (1998) reported that the rapid dissolution of bird feces influenced nutrient content of a body of water over a short period. In contrast, Unckless and Makarewicz (2007) suggested that based on the results of a mesocosm experiment, the impact of bird feces would not become instantly evident and the additional nutrient input from the feces would settle quickly into the sediment. Nakamura et al. (2010) reported that the size of the wintering waterfowl population immediately influenced the TN content, but the TP content peaked one month after the wintering birds had left. Availablity of nutrients and nutrient content of surface water are subject to many variables such as biological consumption, absorption into sediments, decomposition, and mixing events (Unckless and Makarewicz 2007, Nakamura et al. 2010). In the present experiment in which the rice was grown in pots with soil from paddy fields, the contents of available nutrients in the surface water decreased at first then increased after one month.

Although Ganning and Wulff (1969) and Nakamura et al. (2010) argued that the nutrients from feces were primarily taken up by algae, their results were based on the experiment in rockpools and ponds, respectively. However, the increased nutrient content from fecal additions was likely used by the rice plants in the present study. Nutrient content decreased with rice growth, and the total sum of shoot height and shoot number increased with the nutrient amount available during the period over which the nutrient content increased (Figs. 2 and 4). These results support the idea that additional nutrient input from feces could be directly absorbed by rice plants and influence rice growth.

The tillering stage in the present study occurred around the same time that the nutrient content in the surface water was significantly different among the treatments (Figs. 2 and 4a). The tillering stage is important in that it increases the leaf area for photosynthesis and the ear number. Increased nutrient availability tends to stimulate the tillering of rice (Yoshida and Hayakawa 1970, Yoshida 1981). The present study also supports the idea that the nutrient increase from bird feces is closely connected with the increased number of rice shoots. That is, the plots containing $80 \mathrm{~g}$ of feces and subsequent statistically significant increase in nutrient content showed a relatively greater number of rice shoots than the control and plots containing $40 \mathrm{~g}$ of feces which did not exhibit a statistically different increase in nutrient content.

The addition of fecal matter on straw decomposition rate resulted in a timely contribution to the tillering phase of rice plants. At the fourth week, the decomposition rate, as well as the nitrate and phosphate present in the surface water, were different among treatments (Figs. 2 and 5). This supports the concept that the presence of additional nutrients due to the presence of feces tends to positively stimulate the decomposition of rice straws (Elwood et al. 1981). The rapid decomposition rate of rice straws indicates an increase in available nutrients. Therefore, the addition of fecal matter leads to an increase nutrient supply by stimulating the decomposition of fallen rice straws. In addition, the tillering stage of rice occurred at about 


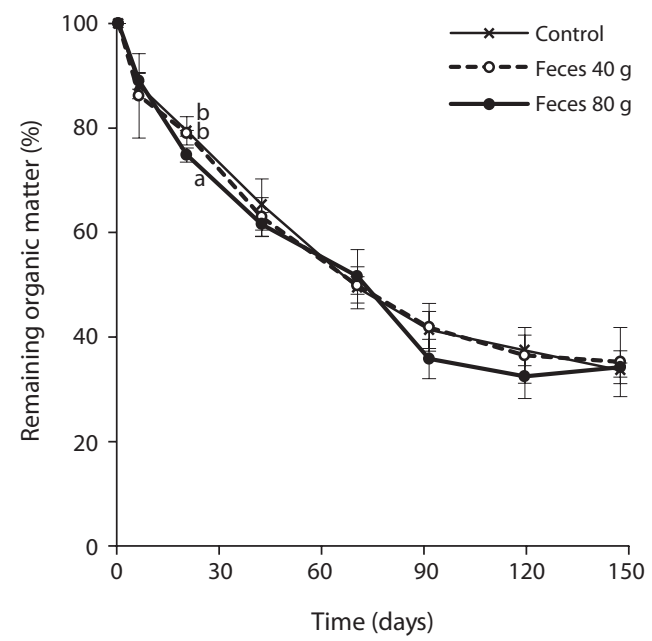

Fig. 5. Change of remaining organic matter in straw during period of growth. Error bars indicate 1 standard error. Alphabets indicate the result of Tukey's post hoc test.

the same time as decomposition was stimulated, which might have worked in the rice plants' favor during the tillering stage despite there being no difference in the rate of decomposition at the end of the experiment.

Although the shoot number was similar between the control and the plots containing $40 \mathrm{~g}$ of feces, the average of rice biomass and soil nutrients was higher in the plots containing $40 \mathrm{~g}$ of feces than in the control plots (Figs. 3 and 6). In the case of TP in the soil, the final content was not different from the initial content in the plots containing $40 \mathrm{~g}$ of feces but was higher in the plots containing 80 $\mathrm{g}$ of feces (Fig. 3d). These results indicate that despite not having an instantaneous impact, nutrients from waterfowl's feces flowing into rice paddy fields have the potential to influence rice growth over the long term. Therefore, if rice paddy fields can be increasingly used as a habitat for wintering waterfowl, this may have a nutritionally favorable impact on conditions for rice plant growth in these fields.

We found that waterfowl's feces positively impact rice plant growth. Thus, rice plant growth could be promoted by the presence of more wintering waterfowl populations in paddy fields. Although Lee et al. (2006) argued that many waterfowl could cause damage to the crops, our results support the concept that the inhabitation of paddy fields by wintering waterfowl has a favorable impact on rice growth. Therefore, our discussion lends credence to the idea that conservation and creation of more paddy field habitats for wintering waterfowl may increase the agricultural and ecological value of these fields.

The present study investigated the impact of birds'

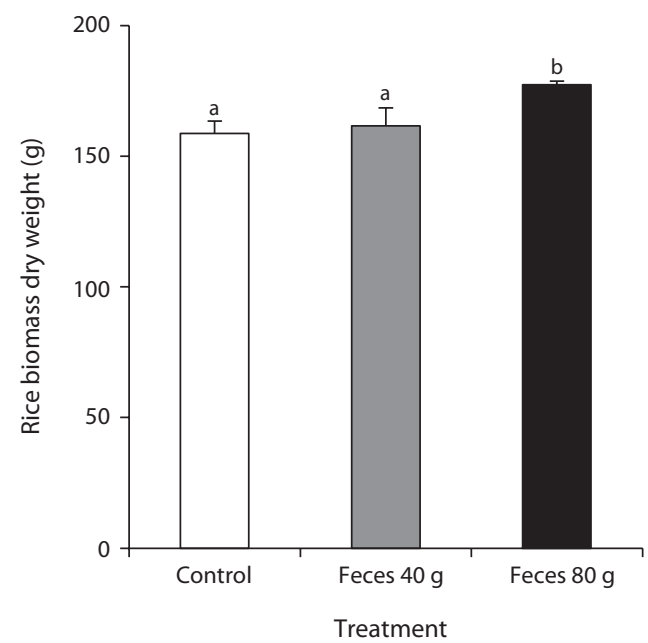

Fig. 6. Dry weight of rice biomass after harvest. Error bars indicate 1 standard error. Alphabets indicate the result of Tukey's post hoc test.

feces on nutrient availability under controlled conditions. With regard to nutrient cycling, the conditions in the greenhouse environment of this study were different from those found in the real environment of paddy fields. In paddy fields, the inflow and outflow of nutrients occur via complicated and highly variable routes (Reddy 1982, Cho et al. 2000). Wintering waterfowl can have additional influences on rice growth by the feeding behavior (Cargill and Jefferies 1984, van Groenigen et al. 2003). Therefore, although the present study showed the potential of wintering waterfowl's feces to favorably impact rice growth, further experiments on paddy fields are needed. These will help deepen our understanding of the ecological impact of waterfowl flocks on the ecosystem of paddy fields.

\section{CONCLUSION}

To investigate the effects of wintering waterfowl's feces on nutrient fluctuation, rice growth, and decomposition of rice straws, their feces were added to paddy soils for rice transplanting. In this study, effects were not immediately observed. However, the nutrient content in the surface water increased over the month following the addition of feces. During this period, the greater the amount of feces added, the greater the increase in available nutrients. In addition, the decomposition of rice straws was facilitated, supplying even more nutrients to the experimental environment. The nutrient level rapidly decreased during the tillering stage when the rice needs more nutrients. The treatments with more available nu- 
trients exhibited a greater number of rice shoots, resulting in an overall increase in production. In the natural environment, the potential impacts of waterfowl's feces are affected by rice decomposition and seasonality in ways that are not entirely predictable. In conclusion, the addition of waterfowl's feces has a positive impact on rice growth. Our results support the concept that increased waterfowl inhabitation of paddy fields can positively influence rice plant growth.

\section{ACKNOWLEDGMENTS}

This study was supported by a Korean Research Foundation Grant funded by the Korean Government (MOEHRD; KRF-2007-313-C00735 and 2012R1A1A2001007). We thank M. G. Hong for his constructive comments that improved an earlier version of the manuscript.

\section{LITERATURE CITED}

Cargill SM, Jefferies RL. 1984. The effects of grazing by lesser snow geese on the vegetation of a sub-artic salt marsh. J Appl Ecol 21: 669-686.

Chaichana R, Leah R, Moss B. 2010. Birds as eutrophicating agents: a nutrient budget for a small lake in a protected area. Hydrobiologia 646: 111-121.

Cheng-fang L, Cou-gui C, Jin-ping W, Ming Z, Wei-ling Y, Ahmad S. 2008. Nitrogen losses from integrated rice-duck and rice-fish ecosystems in southern China. Plant Soil 307: 207-217.

Cho JY, Han KW, Choi JK. 2000. Balance of nitrogen and phosphorus in a paddy field of Central Korea. Soil Sci Plant Nutr 46: 343-354.

Elwood JW, Newbold JD, Trimble AF, Stark RW. 1981. The limiting role of phosphorus in a woodland stream ecosystem: effects of $\mathrm{P}$ enrichment on leaf decomposition and primary producers. Ecology 62: 146-158.

Ganning B, Wulff F. 1969. The effects of bird droppings on chemical and biological dynamics in brackish water rockpools. Oikos 20: 274-286.

Ishida A. 1997. Seed germination and seedling survival in a colony of the common cormorant, Phalacrocorax carbo. Ecol Res 12: 249-256.

Isobe $\mathrm{K}$, Yamaguchi $\mathrm{K}$, Okumura K, Yamamoto $\mathrm{M}$, Asano H, Ishii R. 2005. Characteristics as fertilizer of feces of aigamo ducks for rice plant (Oryza sativa L.). Plant Prod Sci 8: 203-208.

Kamphake LJ, Hannah SA, Cohen JM. 1967. Automated analysis for nitrate by hydrazine reduction. Water Res 1 : 205-216.

Kang TH, Lee KS, Yoo SH, Kim IK, Cho HJ, Kim HJ, Lee JB. 2008. A study on the community characteristics of wintering waterbirds in Hangang river, Korea. Korean J Ornithol 15: 51-59.

Kelly JM, Henderson GS. 1978. Effects of nitrogen and phosphorus additions on deciduous litter decomposition. Soil Sci Soc Am J 42: 972-976.

Kim JG, Park JH, Choi BJ, Shim JH, Kwon GJ, Lee YW, Lee BA, Ju EJ. 2004. Method in Ecology. Bomundang, Seoul. (in Korean)

Lee CW, Kim GY, Jang JD, Joo GJ. 2006. Evaluation of winter barley fields as feeding habitat for waterfowl in the Dongup Reservoir system, Korea. J Ecol Field Biol 29: 165-169.

Lee WS, Park CR, Rhim SJ. 2000. Characteristics of bird community in Han river area. Korean J Ecol 23: 273-279.

Lee WS, Park CR, Rhim SJ, Hur WH. 2001. Characteristics, protection and management of bird community in Geum river estuary. Korean J Ecol 24: 181-189.

Liddicoat ML, Tibbits S, Butler EI. 1975. The determination of ammonia in seawater. Limnol Oceanogr 20: 131-132.

Manny BA, Johnson WC, Wetzel RG. 1994. Nutrient additions by waterfowl to lakes and reservoirs: predicting their effects on productivity and water quality. Hydrobiologia 279/280: 121-132.

Nakamura M, Yabe T, Ishii Y, Kamiya K, Aizaki M. 2010. Seasonal changes of shallow aquatic ecosystems in a bird sanctuary pond. J Water Environ Technol 8: 393-401.

Nam JM, Yoon J, Kim H, Kim JG. 2008. Plant settlement patterns and their effects on breeding sites of little terns (Sterna albifrons) on sand bars on Ganwol Lake. J Ecol Field Biol 31: 37-43.

Pae SH, Park JY, Kim JH, Yoo JC. 1995. Habitat use by wintering waterbirds at Han River estuary and Imjin River, Korea. Korea J Ornithol 2: 11-21.

Pettigrew CT, Hann BJ, Goldsborough LG. 1998. Waterfowl feces as a source of nutrients to a prairie wetland: responses of microinvertebrates to experimental additions. Hydrobiologia 362: 55-66.

Purcell SL, Goldsborough LG. 1996. Waterfowl feces as a source of nutrients to planktonic and benthic algae in Delta Marsh. UFS (Delta Marsh) Annu Rep 31: 24-29.

Reddy KR. 1982. Nitrogen cycling in a flooded-soil ecosystem planted to rice (Oryza sativa L.). Plant Soil 67: 209-220.

Rejmánková E. 2011. The role of macrophytes in wetland ecosystems. J Ecol Field Biol 34: 333-345.

Solorzano L. 1969. Determination of ammonia in natural waters by the phenolhypochlorite method. Limnol Ocean- 
ogr 14: 799-801.

Tomassen HBM, Smolders AJP, Lamers LPM, Roelofs JGM. 2005. How bird droppings can affect the vegetation composition of ombrotrophic bogs. Can J Bot 83: 10461056.

Unckless RL, Makarewicz JC. 2007. The impact of nutrient loading from Canada Geese (Branta canadensis) on water quality, a mesocosm approach. Hydrobiologia 586: 393-401.

van Groenigen JW, Burns EG, Eadie JM, Horwath WR, van Kessel C. 2003. Effects of foraging waterfowl in winter flooded rice fields on weed stress and residue decomposition. Agric Ecosyst Environ 95: 289-296.

Villegas-Pangga G, Blair G, Lefroy R. 2000. Measurement of decomposition and associated nutrient release from straw (Oryza sativa L.) of different rice varieties using a perfusion system. Plant Soil 223: 1-11.

Yoshida S. 1981. Fundamentals of Rice Crop Science. Los Baños, Laguna.

Yoshida S, Hayakawa Y. 1970. Effect of mineral nutrition on tillering of rice. Soil Sci Plant Nutr 16: 186-191. 